\title{
An epidemiological study of injury among urban population
}

\section{Ghimire $A^{1}$, Nagesh $S^{2}$, Jha $\mathbf{N}^{1}$, Niraula $S^{1}$, Devkota $S^{3}$}

${ }^{1}$ School of Public Health and Community Medicine, B. P. Koirala Institute of Health Sciences, Dharan, Nepal; ${ }^{2}$ Department of Community Medicine, Lady Harding Medical College, New Delhi, India, ${ }^{3}$ Kalanet Project, B. P. Koirala Institute of Health Sciences, Dharan, Nepal

\begin{abstract}
Background: Injuries are a focus of public health practice because they pose a serious health threat, occur frequently and are preventable. Injuries affect people of all ages and range from minor cuts and bruises to major catastrophes that take thousands of lives.

Objectives: This paper aims to find out the prevalence of injuries and to study the various epidemiological factors related to the injuries in Dharan.

Materials and methods: A sample of 1398 households was taken as study sample. A systematic random sampling technique was used to select the $10 \%$ households from each 19 wards. A pre-tested questionnaire was used to collect demographic information and information related to injuries to the persons suffered from injuries.

Result: The prevalence of minor injury in Dharan was 3.5\% per month. The injury was common in the age group, 40-49 years $(4.6 \%)$ and majority of injured persons were farmers $(6.9 \%)$. Home was the common place $(55.6 \%)$ for the minor injury. Cut/stab (32.8\%) was the most common types of minor injury. The prevalence of major injury was $0.7 \%$ per year and occurred more among 50-59 years age group (1.7\%). The commonest place for major injury was at road (53.1\%) and service holders were at more risk (1.4\%). Falls from the height $(46.9 \%)$ were the most common types of major injury.

Conclusion: The injuries related to lifestyle profession and road traffic accidents (RTA) is the commonest burden revealed in the study sample. Promotion of safety and education for protection at work and safe driving can prevent the major socio-economic loss to the family and community at large.
\end{abstract}

Key words: Minor injury, Major injury, RTA, Epidemiological factors.

Tnjury had long been considered as an "accident" 1 and has been taken as a medico-legal and a criminal perspective but not taken as a public health problem. Once a person comes in health institution for treatment of an injury, only then it is considered a health problem ${ }^{1}$. Injuries are a focus of public health practice because they pose a serious health threat, occur frequently and are preventable ${ }^{2}$. Modernisation created hostile environment for accidental injuries everywhere, which toll large number of morbidity and mortality among young people and children. Information available are merely record based, which is just tip of the iceberg. Problem of the accidental injury can be recognised only through community based epidemiological studies in different regions.

This study was conducted in Dharan municipality, a town of the Eastern region of Nepal, which provides the magnitude of the problem in Dharan. This paper aims to find out the prevalence of injuries and to study the various epidemiological factors related to the injuries in a rapidly urbanising town, Dharan, which includes minor and major injuries.

\section{Materials and methods}

This study is a cross-sectional study conducted from July 2004 to June 2005 in Dharan municipality. Dharan is a town situated at the foot of the mighty Himalayas in the Eastern region of Nepal. This town is one of the most important industrial, economic and educational centres in the region and a gate-way to the hills and mountains of the Eastern Nepal. The population of Dharan Municipality was 95332 with 13853 households, according to the census 2002; it is divided in to 19 wards. It has mixed ethnicity comprising of Rai, Newar, Limbu, Brahmin, Chhetri, Tamang, Magar, Gurung and others ${ }^{3}$. In this study $10 \%$ of the households of Dharan i.e. 1388

Correspondence

Dr. Anup Ghimire

Assistant Professor

School of Public Health and Community Medicine

B.P. Koirala Institute of Health Sciences, Dharan, Nepal.

E-mail: ghimire.anup@gmail.com 
households was taken as a sample size. A systematic random sampling technique was used to select $10 \%$ households from each 19 wards. Hence, the number of household from each ward ranged from 20 to 190 based on the total number of households in a particular ward. A detailed questionnaire was used to collect demographic information of all members of each households and information related to injuries to the persons suffered from injuries including treatment obtained, cost of treatment (direct/indirect cost) and length of disability. A separate questionnaire with in depth interview and probe was done to collect any information related to a fatal injury within one year among family members. Preliminary analysis indicated that a long recall period underestimated annual injury rates, with the effect being greater for injuries resulting in $<30$ disability days while the rates for injuries resulting in 30 or more disability days were quite stable 5 . We therefore categorised severity of injury as 'minor' if resulting in less than 30 days of lost of activity and 'major' if resulting in 30 or more days of lost activity.

A master chart was prepared and the collected data was entered in Microsoft Excel. Coding of the variables was done. SPSS version 11.5 was used for analysis and percentage, proportions and prevalence rates were calculated. Chi-square test was applied to test for proportions wherever applicable.

\section{Results}

Out of total number of 13853 households having a total population of 95332 in Dharan municipality, 1388 households having 7063 persons (i.e. $10 \%$ of the households of Dharan) were interviewed during the study period.

The prevalence of minor injuries was highest (4.6\%) among 40-49 years age group, followed by $4.5 \%$ among 0-9 years. But the prevalence of major injuries was the highest (1.7\%) among 50-59 years of age group, followed by $30-39$ years and 20-29 years age groups, $1.0 \%$ and $0.7 \%$ respectively. The difference in the prevalence of both injuries according to the age-group is statistically not significant. The prevalence of injury among the males is significantly higher in comparison with females for minor injuries $(\mathrm{p}<0.0001)$ and major injuries $(\mathrm{p}<0.005)$ (Table 2).
Minor injuries accounted more (4.0\%) in those with intermediate and above education. The least prevalence was among illiterates (3.0\%). Among major injuries, highest $(1.0 \%)$ prevalence was found among primary school education, followed by secondary school education $(0.7 \%)$.

Table 2 shows that the prevalence of minor injury was also highest $(6.9 \%)$ among agriculture and farming by occupation. Likewise the prevalence of major injuries was more among those who were in agriculture field.

Maximum number (19.2\%) of minor injuries occurred on Saturday, follows by Sunday and Monday, $17.2 \%$ and $14.4 \%$ respectively. Major injuries occurred maximum $(24.5 \%)$ on Sunday (Fig. 1). Similarly $22.4 \%$, 16.3\%, $14.3 \%$ and $10.2 \%$ of the major injuries occurred on Saturday, Friday, Thursday and Monday respectively.

Data indicates that minor injuries occurred most frequently at $3 \mathrm{pm}$ to $5: 59 \mathrm{pm}(26 \%)$ and followed by $21.6 \%$ at 9:00 am to $11: 59 \mathrm{am}$. Very less number (1.2\%) of minor injuries occurred during 1:00 am to 5:59 am. Maximum percentage $(30.6 \%)$ of major injuries had occurred at $3: 00 \mathrm{pm}$ to $5: 59 \mathrm{pm}$, followed by $6: 01 \mathrm{pm}$ to $1: 00$ am $20.4 \%$. Only (6.2\%) of major injuries occurred during 6:00 am to 8:59 am.

In terms of minor injuries, most of them (55.6\%) occurred at home, followed by road and recreation area (including sports): $21.6 \%$ and $20.0 \%$ respectively. Most of the major injury (53.1\%) occurred at road, followed by home (42.9\%) and recreation area (including sports) $(4.1 \%)$.

Fall and transport injuries were the most common causative mechanism for major injuries whereas cut/stab was also additional causes to the causative mechanism for minor injuries (Table 3 ).

Table 1 shows that out of the total surveyed population of 7063, prevalence of minor injuries were 3.5\% during the preceding recall of one month and major injuries were $0.7 \%$ during preceding recall of one year. Four deaths due to injuries were also reported during the preceding one-year.

Table 1: Prevalence of injuries in the study population $(n=7063)$

\begin{tabular}{|l|c|c|}
\hline Types of injuries & Number & Prevalence, \% (95\% CI) \\
\hline Minor injury & 250 & $3.5(3.1$ to 4.0$)$ \\
\hline Major injury & 49 & $0.7(0.5$ to 0.9$)$ \\
\hline
\end{tabular}


Table 2: Prevalence of different types of injuries according to the various demographic variables

\begin{tabular}{|c|c|c|c|c|}
\hline \multirow[b]{2}{*}{ Variables } & \multicolumn{4}{|c|}{ Prevalence (\%) } \\
\hline & \begin{tabular}{l|} 
Minor \\
Injury \\
\end{tabular} & significance & $\begin{array}{l}\text { Major In- } \\
\text { jury }\end{array}$ & significance \\
\hline \multicolumn{5}{|l|}{ Age group (Year) } \\
\hline $0-9$ & 4.5 & \multirow{7}{*}{$\chi^{2}=7.06$, d.f. $=6, p=0.32, \mathrm{NS}$} & 0.6 & \multirow{7}{*}{$\chi^{2}=14.8$, d.f. $=6, p=0.21, \mathrm{NS}$} \\
\hline $10-19$ & 3.0 & & 0.6 & \\
\hline $20-29$ & 3.3 & & 0.7 & \\
\hline $30-39$ & 3.2 & & 1.0 & \\
\hline $40-49$ & 4.6 & & 0.1 & \\
\hline $50-59$ & 3.3 & & 1.7 & \\
\hline$\geq 60$ & 3.3 & & 0.4 & \\
\hline \multicolumn{5}{|l|}{ Gender } \\
\hline Male & 4.5 & \multirow{2}{*}{$\begin{array}{c}\chi^{2}=19.41, \text { d.f. }=1 \\
p<0.0001, S\end{array}$} & 1.1 & \multirow{2}{*}{$\chi^{2}=9.75$, d.f. $=1, p<0.005, S$} \\
\hline Female & 2.6 & & 0.4 & \\
\hline \multicolumn{5}{|l|}{ Education* } \\
\hline Illiterate & 3.0 & \multirow{2}{*}{$\chi^{2}=0.947$, d.f. $=1, p=0.33, \mathrm{NS}$} & 0.5 & \multirow{2}{*}{$\chi^{2}=0.372$, d.f. $=1, p=0.54, \mathrm{NS}$} \\
\hline Literate & 3.5 & & 0.7 & \\
\hline Primary & 3.5 & & 1.0 & \\
\hline Secondary & 3.3 & & 0.7 & \\
\hline Intermediate and above & 4.0 & & 0.6 & \\
\hline \multicolumn{5}{|l|}{ Occupation* * } \\
\hline Student & 3.5 & \multirow{9}{*}{$\chi^{2}=15.79$, d.f. $=8, p=0.06, \mathrm{NS}$} & 0.6 & \multirow{9}{*}{ NA } \\
\hline Housewife & 2.9 & & 0.4 & \\
\hline Business & 4.0 & & 0.6 & \\
\hline Unemployed & 5.0 & & 0.8 & \\
\hline Service & 3.6 & & 1.4 & \\
\hline Agriculture/Farming & 6.9 & & 1.1 & \\
\hline Retired & 3.4 & & 1.3 & \\
\hline Labour & 1.3 & & 1.3 & \\
\hline Others & 1.9 & & 0.9 & \\
\hline
\end{tabular}

* Children aged $<6$ years $(\mathrm{n}=327)$ not applicable for education

** Children aged $<10$ years $(\mathrm{n}=601)$ not applicable for occupation

NS: not significant /S: significant

NA: not applicable (less number of frequency in many cells)

Table 3: Distribution of injuries according to the causative mechanism

\begin{tabular}{|l|c|c|c|c|}
\hline \multirow{2}{*}{ Mechanism } & \multicolumn{3}{|c|}{ Type of injury } \\
\cline { 2 - 5 } & \multicolumn{2}{|c|}{ Minor } & \multicolumn{2}{c|}{ Major } \\
\cline { 2 - 5 } & No. & \% & No & \% \\
\hline Cut/stab & 82 & 32.8 & 2 & 4.1 \\
\hline Fall & 81 & 32.4 & 23 & 46.9 \\
\hline Transport injuries & 25 & 10.0 & 20 & 40.8 \\
\hline Burn/scald & 23 & 9.2 & 3 & 6.1 \\
\hline Bite (animal/insects) & 11 & 4.4 & 0 & 0 \\
\hline Assault & 11 & 4.4 & 1 & 2.1 \\
\hline Struck by objects & 6 & 2.4 & 0 & 0 \\
\hline Other & 11 & 4.4 & 0 & 0 \\
\hline Total & $\mathbf{2 5 0}$ & $\mathbf{1 0 0 . 0}$ & $\mathbf{4 9}$ & $\mathbf{1 0 0 . 0}$ \\
\hline
\end{tabular}




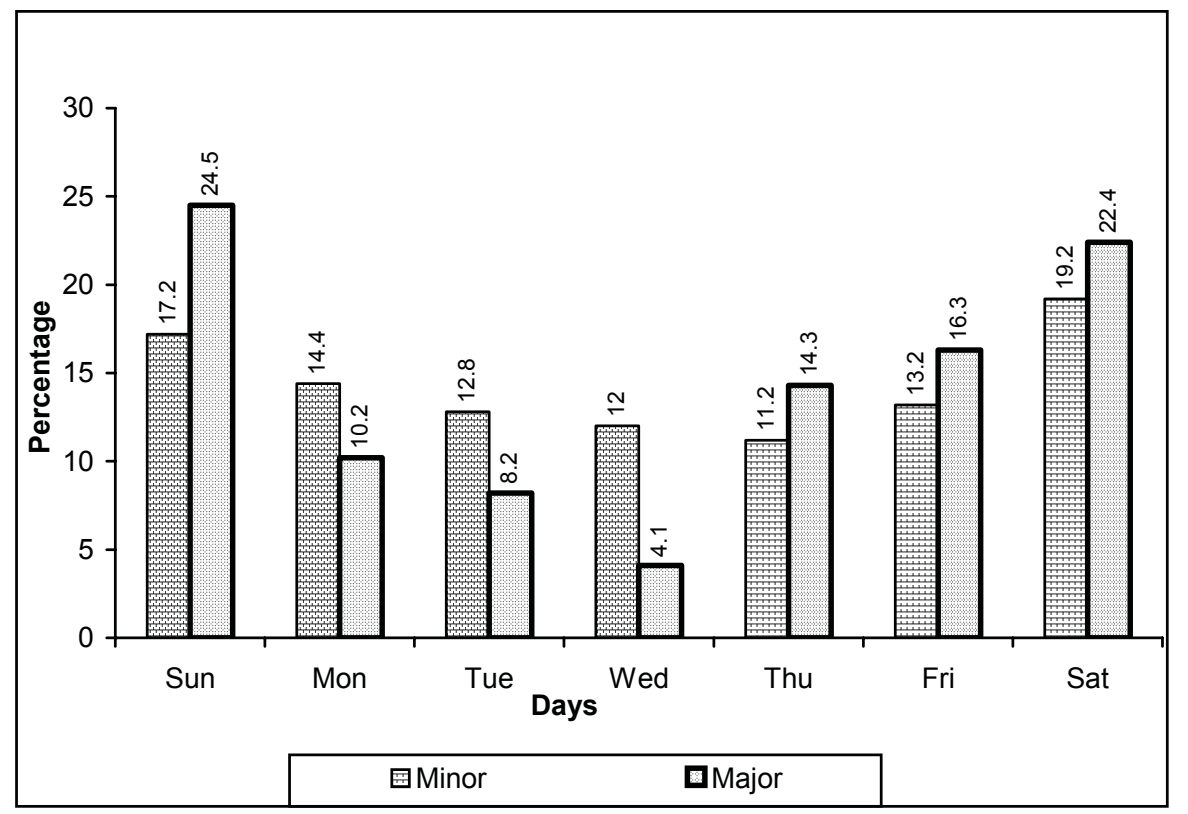

Fig 1: Distribution of injuries according to the day of occurrence

\section{Discussion}

The present study revealed that prevalence rate of minor injury was $3.5 \%$ per month and for major injuries $0.7 \%$ per year. A study from Ghana ${ }^{4}$ showed that the incidence rate of minor injuries among the urban community was $1.3 \%$ and that of major injury was $1.7 \%$. Another study done in urban area of Tanzania ${ }^{5}$ showed that the incidence rate of minor injury was $1.7 \%$ and major injury $0.83 \%$. Compared to these studies, the prevalence of minor injuries was more in our context whereas the prevalence of major injuries was less. Also, in a study conducted in rural area of eastern Nepal, showed that the prevalence of minor injury was $2.9 \%$ per month and major injury was $0.04 \%$ per year ${ }^{6}$. The prevalence of injury was higher in our study as compare to study done in rural area of Nepal. This could be due to rapid urbanisation and unplanned urban growth of Dharan which has led to incompatible land uses with high levels of pedestrian vehicle conflict and also increasing motorization, crowded living conditions and lack of recreation space. Similar trends was observed in some the studies ${ }^{6,7}$.

The age specific prevalence of both injury was highest among 0-9 years age group (5.1.\%), followed by 50 59 years age group (5.0\%) and 40-49 years age group 4.7\%. In Kumasi Ghana also found maximum incidence in 0-9 year's age group ${ }^{8}$. A hospital-based study in eastern $\mathrm{Nepal}^{9}$ showed that 0-40 year was the most commonly injured group. Similarly, a study done by Oliver BA found that most prone group for accident was
5-25 years ${ }^{10}$. In Tanzania, maximum participants were among 15-44 years age group ${ }^{5}$. This shows that the age may be an important risk factor for many injuries but its influence varies among specific injury groups. Injuries are quite common in age group between 0-9 years in this study because of the range and extent of their activities which exposé them to such episodes.

In the present study, males were injured more (minor $4.5 \%$ and major $1.1 \%$ ) than the females, which is supported by many studies done in Ontario of Canada ${ }^{11}$, in Pakistan ${ }^{12}$, in Valencia of Spain ${ }^{10}$, in Eastern Nepal ${ }^{13}$ and in Haryana India ${ }^{14}$. The reason may be due to their involvement in outdoor activities and females leading less active life and mostly remain indoors.

The result also showed that prevalence was more among those who had studied up to or above intermediate (minor $4.0 \%$, and major $0.6 \%$ ), than those of other level of education except for major injures which was more among primary school education. Similar finding was found in other studies ${ }^{5,15}$. It was observed that more people with lower levels of education were involved in injuries. However, this relationship between education and injury may not be causal.

Injury rate according to occupation was seen highest among the agricultural workers / farmers for minor injury $6.9 \%$, but major injury was found more among the service holders (1.4\%). This may be because 
farmers were more involved in fieldwork and in close contact with sharp equipments and tools than in other occupations, which may increase the risk of having an injury. It has been reported that more accidents was seen among low socio-economic group of people. However in another study ${ }^{16}$ major injury was found highest among students $(2.5 \%)$ followed by labourers $2.0 \%$, but in our study it was $0.6 \%$ and $1.3 \%$ respectively.

The highest number of minor and major injuries had occurred on Saturday and Sunday. Similar finding have also been observed by other studies ${ }^{8,6}$. Saturday is a public holiday in Nepal. The reason may be that people leave homes for recreation and other various purposes on Saturday and hence become more exposed to minor injuries. Similarly more people got major injury during $1^{\text {st }}$ day of the week; reason may due to the heavy traffic rush.

In the present study, the peak time for minor injury was $3: 00 \mathrm{pm}$ to $5: 59 \mathrm{pm}(26.0 \%)$, followed by $9: 00$ am to $11: 59$ am $(21.6 \%)$ and $6: 01 \mathrm{pm}$ to $1: 00 \mathrm{am}$ (17.2\%). Similar finding have been observed by the study of Rajbhandari ${ }^{6}$. Morning hours are the busiest as commuters go to the schools, offices, factories and business places and were more prone to injuries. Similarly maximum numbers of major injuries occurred at 3:00 pm to 5:59 pm (30.6\%) (Fig 2) followed by 6:01 pm to $1: 00$ am $(20.4 \%)$. Similar finding was found in a study of Haque $\mathrm{M}$ et al. ${ }^{17}$. These hours were the busiest times as peoples are found returning from the various places after finishing their works and roads are also busy. During this time children usually go to play and hence they were more exposed to different types of injuries. Only $(6.2 \%)$ of people got major injuries at 6:00 am to $8: 59 \mathrm{am}$, it may be because at that time people are at home and roads are also not so busy, hence less chances of injuries at that time.

This highest numbers of minor injuries seemed to be occurring at home $(55.6 \%)$, followed by road $(21.6 \%)$ and recreation areas (including sports) $20.0 \%$. But most of the major injury occurred at road $(53.1 \%)$ and at home $42.9 \%$. The study from the eastern $\mathrm{Nepal}^{6}$, found the most common place for injuries were field/farm (28.9\%), equal percentage $(20.8 \%)$ for road and play ground and $13.1 \%$ at home. This is expected because in rural area most of the people are involved in agricultural work; hence they were more prone to be injured in the field. Also in the present study the most of the major injury occurred at road. This may be because of high levels of pedestrian vehicle conflict and also increasing use of vehicles in Dharan.

Our study also shows that the leading causative mechanism of minor injuries was cut /stab and fall.
Likewise most of the major injuries $(46.9 \%)$ were due to fall followed by transport related injuries $40.8 \%$. Similar findings have also been observed by Mock CN et al. ${ }^{4}$. Fall was the single largest contributor, followed by transport related injury. In a previous hospital based study ${ }^{18}$, it was reported transport related admission for children (40\%), followed by falls (27\%). However, transport related injuries accounted for over half(54.0\%) of injury related mortality in that study, showing that although falls are a significant contributor to nonfatal injuries, transport injury is the most important contributor for fatal injuries.

\section{Conclusion}

The prevalence rate of minor injury was $3.5 \%$ per month and for major injuries $0.7 \%$ per year.

Injury rate was seen highest among the agricultural workers / farmers for minor injury but major injury was found more among the service holders. The highest number of minor and major injuries had occurred on Saturday and Sunday. The leading causative mechanism of minor injuries was cut /stab and fall. The injuries related to lifestyle profession and RTA is the commonest burden revealed in the study sample. Promotion of safety at work and education for protection at work and safe driving can prevent the major socio-economic loss to the family and community at large.

\section{References}

1. Brundtland GH. Injuries in South-East Asia Region priorities for policy and action. Geneva: World Health Organization; 2000 -2002.

2. Jess FK, Corinne P, Dushyanthi V. Injury control: The public Health Approach. Inc: Maxcy - Rosenau- last Public Health and preventive medicine. Wallace RB, Kohatsu R (editors). 14th edition. UK: McGraw-Hills Professional;1998. 1209-22.

3. B.P. Koirala Institute of Health Sciences. Prospectus of Postgraduate Programme. Dharan: BPKIHS; 2003.

4. Mock CN, Abatanga F, Cummingi P, Koepsell TD. Incidence and outcome of injury in Ghana: A community based survey. WHO Health Bulletin. 1999; 77:12.

5. Moshiro C, Heuch I, Astrom AN, Setel P, Hemed Y, Kyle G. Injury mobility in an urban and a rural area in Tanzania: an epidemiological survey. BMC Public Health. 2005, 5:11.

6. Rajbhandari SD, Jha N, Niraula SR, Nagesh S. Prevalence of different types of injury in a rural community of Eastern Nepal. Unpublished Thesis work, BPKIHS. 2002. 
7. Gumber A. Burden of injury in India. Utilization and Expenditure pattern. 1993. 88:1-46.

8. Salifu IM, Mock C. Pedestrian injuries in Kumasi results of an epidemiologic survey. The Ghana Engineer. 1998; 23-7.

9. Singh S. Trauma Epidemiology in Eastern Nepal. Journal of the Institute of Medicine. 1996; 18: 149-54.

10. Oliver BA, Civera CP. Epidemiological study of accidents attended in a non- hospital emergency service. Aten Primaria. 1998 ; 21: 522-6.

11. Pickett W, Brison RJ, Niezgoda H, Chipman ML. Non fatal farm injuries in Ontario: A population-based survey. Accidental Anal Preview. 1995; 4: 425-33.

12. Ahmed M, Shah M, Luby S, Drago-Johnson P, Wali S. Survey of Surgical Emergencies in a rural population in the northern Area of Pakistan. Journal of Tropical Medicine and International Health. 1999; 4(12): 846-57.

13. Jha N. Road Traffic Accident cases of BPKIHS, Dharan, Nepal: one year in retrospect. Journal of the Nepal Medical Association. 1997; 35(122): 241-4.
14. Singh R, Sharma CS, Mittal R, Sharma A. Traumatic spinal cord injuries in Haryana: An epidemiological study. Indian Journal of Community Medicine. 2003; 28 (4): 184-6.

15. Jha N, Srinivasa DK, Roy G, Jagdish S. Epidemiological Study of Road Traffic Accidents cases: A study from south India. Indian Journal of Community Medicine. 2004; 29 (1): 20-4.

16. Jolly MF, Fogging MP, Less BI. Geographical and socio-ecological variations of traffic accidents among children. Social Sciences and Medicine. 1991; 22(7): 765-9.

17. Haque M, Zabbar MA. Injury pattern of the victims attending the one stop crisis centre of Dhaka medical college Hospital, 2003. Second Asia Regional conference on safe communities and First Bangladesh conference on injury prevention; 2004.p. 96.

18. Abatanga FA, Mock CN. Childhood injuries in an urban area of Ghana: A hospital based study of 677 cases. Pediatric Surgery International. 1998; 13: 515-8. 